\title{
OS DESAFIOS DA FUNDAMENTAÇÃO DA DIGNIDADE HUMANA
}

\section{Paulo Umberto Stumpf}

Graduação em Ciências Jurídicas e Sociais pela Universidade do Vale do Rio dos Sinos (1993), graduação em Bacharel em Filosofia pela Faculdade Jesuíta de Filosofia e Teologia (1989), graduação em Licenciatura Plena em Filosofia pela Universidade do Vale do Rio dos Sinos (1990), graduação em Teologia pela Faculdade Jesuíta de Filosofia e Teologia (1997), mestrado em Direito pela Universidade Federal de Minas Gerais (1997) e doutorado em Direito pela Universidade Federal de Minas Gerais (2004). Reitor da Escola Superior Dom Helder Câmara. Atualmente desenvolve Atividade Extraclasse na Escola Superior Dom Helder Câmara, Diretor Geral da Fundação Movimento Direito e Cidadania e Diretor Geral da Revista Eletrônica Dom Total.

FRANCISCO HAAS

Francisco Haas. Doutorando em Teoria do Estado e Direito Constitucional da Puc Rio. Mestrado pela Pontifícia Universidade Católica de Minas Gerais (2001), Pós-graduação em Filosofia (1992) e licenciatura em Filosofia, História pela Pontifícia Universidade Católica do Paraná (1991), graduação em Filosofia pelo Centro de Estudos Superiores da Companhia de Jesus (1989), graduação em Teologia pelo Centro de Estudos Superiores da Companhia de Jesus (1994). Atualmente é Pró-reitor de Extensão, Supervisor Administrativo e professor de Sociologia da Escola Superior Dom Helder Câmara, Coordenador do Movimento Ecos.

\section{Resumo}

Na sociedade contemporânea os direitos do ser humano e da sociedade chegam à convicção ética de que a pessoa humana é sempre um fim e jamais um meio e de que todo o poder somente se legitima à medida que se faz mediação da justiça e do bem comum dos cidadãos e da natureza. Que todo desenvolvimento técnico deve ser orientado para a promoção integral da pessoa humana e dos povos. Habermas discute o conceito de dignidade humana e a utopia realista dos Direitos Humanos a partir da declaração da inconstitucionalidade da Lei de Segurança Aérea Alemã. Pelè discute a tensão entre as bases teóricas da dignidade humana e suas implicaçóes práticas. Stumpf analisa o conceito da dignidade humana subjacente no imperativo categórico kantiano e finalmente apresentaremos a dignidade humana como fonte moral dos direitos humanos. 


\section{Palavras-chave}

Dignidade humana; Direitos humanos; Desafios teóricos/práticos; Kant.

\section{Resumen}

En la sociedad contemporánea los derechos del hombre y de la sociedad llegan a la convicción ética de que la persona humana es siempre un fin y nunca un medio y que todo el poder sólo es legítimo en la medida en que se hace la mediación de la justicia y del bien común de los ciudadanos y de la naturaleza. Que todo el desarrollo técnico debe orientarse hacia la promoción integral de la persona humana e de los pueblos. Habermas discute el concepto de la dignidad humana y la utopía realista de los derechos humanos a partir de la declaración de inconstitucionalidad de la Ley de Seguridad Aérea Alemana. Pelè analiza la tensión entre los fundamentos teóricos de la dignidad humana y sus implicaciones prácticas. Stumpf examina el concepto de dignidad humana que subyace en el imperativo categórico kantiano y finalmente presentar la dignidad humana como fuente de la moral de los derechos humanos.

\section{Palabras clave}

La dignidad humana; Los derechos humanos; Los desafíos teóricos/prácticos; Kant.

\section{Introdução}

Este artigo visa discutir a problemática em torno da definição conceitual da dignidade humana e seus desafios práticos. As análise se dão em torno do artigo de Pelè (2004) "una aproximación al concepto de dignidad humana" e alguns apontamento de sua tese de doutorado; a tese de doutorado do Stumpf (2010) "O princípio constitucional da dignidade humana", e o artigo de Habermas (2010) "O conceito de dignidade humana e a utopia realista dos direitos humanos", entre outros autores.

$\mathrm{Na}$ sociedade contemporânea os direitos do ser humano e da sociedade chegam à convicção ética de que a pessoa humana é sempre um fim e jamais um meio e de que todo o poder somente se legitima à medida que se faz mediação da justiça e do bem comum dos cidadáos e da natureza. Que todo desenvolvimento técnico deve ser orientado para a promoção integral da pessoa humana e dos povos.

A problemática de nossa discussão iniciará em torno da fundamentação moral do artigo de Habermas "o conceito de dignidade humana e a utopia realista dos Direitos Humanos", que analisa a declaração do Tribunal Constitucional Federal sobre a inconstitucionalidade da Lei de Segurança Aérea Alemã, diante da intangibilidade da dignidade humana. Num segundo momento a discussão dar-se-á em torno da tensão entre as bases 
teóricas da dignidade humana e suas implicaçóes práticas apresentadas por Pelè. Em terceiro lugar analisaremos a dignidade humana subjacente no imperativo categórico kantiano a partir de Stumpf que chama a atenção sobre a formulação do imperativo categórico de Kant e a dignidade humana e finalmente apresentaremos a dignidade humana como fonte moral dos direitos humanos. Procuramos desenvolver uma análise dedutiva através da pesquisa exploratória, baseado em levantamento bibliográfico.

\section{A Dignidade Humana como Direito Absoluto}

Para Habermas (2010) no imperativo categórico de Kant ${ }^{1}$ cada pessoa goza de direitos absolutos e nada justificaria sacrificar o direito de poucos em proveito dos direitos de muitos, mesmo que fosse através do Estado. Kant em seu imperativo categórico parte do princípio que o homem, pela sua capacidade de autodeterminar suas açóes, também teria autonomia sobre sua própria vontade, característica essa inerente ao seu ser racional, tornando-se o que ele chamou de "um fim absoluto em si mesmo".

Segundo Habermas

O dever estatal (decorrente do art. 2.2 da Lei Fundamental ${ }^{2}$ ) de proteger a vida das vítimas de um potencial ataque terrorista deveria ceder diante do dever de respeitar a dignidade humana dos passageiros: "Ao terem suas vidas dispostas unilateralmente pelo Estado, às pessoas a bordo da aeronave é negado o valor que é devido a um ser humano por si”’. (HABERMAS, 2010, p. 2)

Para Bobbio (2000), na concepção de Kant, a função fundamento do direito era assegurar a garantia das liberdades individuais, através de regras que permitissem a convivência social e a não transgressão das liberdades dos cidadãos. Nesse caso da Lei da Segurança Aérea da Alemanha em 2006, o Tribunal Constitucional Federal considerou inconstitucional a Lei que permitisse a atuação do Estado para além da prescrição de normas que regulassem as liberdades individuais.

Segundo o Habermas (2010) "o conceito filosófico de dignidade humana, que surgiu na Antiguidade e adquiriu sua formulação atual em Kant”, originou-se devido as enormes atrocidades cometidas em nome dos direitos humanos, durante a Segunda Guerra

1 No reino dos fins tudo tem um preço ou uma dignidade. Quando uma coisa tem um preço, pode-se pôr em vez dela qualquer outra como equivalente; mas quando uma coisa está acima de todo o preço, e, portanto náo permite equivalência, entấo tem ela dignidade. (KANT, 1995, p.77)

2 “Todas as pessoas têm direito à vida e à integridade física".

3 BverfG, 1 BvR 357/05 de 15.02.2006, parágrafo 124; sobre o julgamento cf. J.v. Bernstorff, Pflichtenkollision und Menschenwürdegarantie. Zum Vorrang staatlicher Achtungspflichten im Normbereich von Art. 1 GG, Der Staat 47, 2008. 
Mundial, e que a partir de lá tem recebido destaque especial nas constituiçóes nacionais e nos textos do direito internacional. A pergunta que Habermas se faz, porque os Direitos Humanos foram abordados desde o século XVII e somente no Século XX teria emergido o conceito de Dignidade Humana? Para o autor, o processo histórico de atrocidades cometidos contra o homem, durante a segunda guerra mundial, teria feito emergir com mais força o conceito da dignidade humana, expressos de uma forma bem clara nas constituiçóes e tratados internacionais.

É somente no contexto histórico do Holocausto, que a ideia de direitos humanos se tornou retrospectivamente carregado moralmente com o conceito de dignidade humana - e possivelmente sobrecarregada? A carreira recente do conceito de "dignidade humana" nas discussóes constitucionais e internacionais sugere essa ideia. (HABERMAS, 2010, p. 3)

\section{Tensão entre as Bases Teóricas da Dignidade Humana e suas Implicações Práticas}

Pelè em seu artigo, "una aproximación al concepto de dignidad humana" afirma que alguns autores apontam uma certa tensão entre as bases teóricas da dignidade humana e suas implicaçóes práticas.

Vemos que alguns autores observaram uma tensão entre a base teórica da dignidade e suas implicaçóes práticas. A filosofia moral e política atual nos trazem o conceito de dignidade através de casos e a discussão sobre a indignidade de determinadas condiçôes (sociais, psicológicos, etc.) onde se encontram alguns indivíduos ou grupos. (PELÈ, 2004, p. 9, tradução nossa)

Segundo o autor (2004), historicamente houve várias tentativas de uma aproxima-

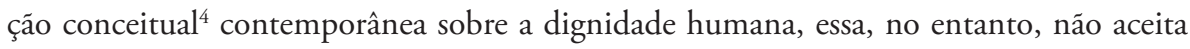
uma explicaçáo racional para o fundamento da dignidade humana, devida a sua complexidade subjetiva e mutável. E o autor, utilizando-se de uma afirmação de Perez, faz uma defesa sobre essa imprecisão ou seu desconhecimento e a ausência da proteçáo efetiva da pessoa, rotulando a conceituação da dignidade humana como "vazia".

No entanto, essas posiçóes tentam evitar abordar a reflexão sobre o fundamento da dignidade, rotulando-a como "vazia", porque eles são realmente incapazes de decifrar sua complexidade. (PELÈ, 2004, p. 2)

4 Sin embargo, la reflexión contemporánea tiende a rechazar cualquier explicación racional al fundamento de la dignidad, considerando que siempre dicha explicación es subjetiva y cambiante; algunos incluso, frente a la presunta incapacidad de definir la dignidad humana, piensan que de todas formas "(...) una fuerza instintiva innata sabrá advertirnos de cuando se desconoce, no se protege o lesiona la dignidad de una persona" (PEREZ, Apud, PELE, 2004, p. 9) 
Diante deste embate teórico, Pelè (2004) procura descrever as várias fases do conceito de dignidade humana. Durante a era pré-moderna, o homem é concebido como a imagem de seu criador, atribuindo-lhe superioridade sobre as demais criaturas. A dignidade humana estava fundamentada na sua imanência originária ${ }^{5}$. Na modernidade esse conceito é reformulado. Com a concepção antropocêntrica, a perspectiva do conceito da dignidade humana deriva de sua natureza humana ${ }^{6}$, dissociado de qualquer origem divina, mantida a sua singularidade da espécie humana em relação aos outros animais. Segundo o autor, essa nova concepção da dignidade tem refletido no campo jurídico com o surgimento dos Direitos Humanos, definindo a superioridade dos seres humanos sobre os animais e criando o conceito de igualdade entre os humanos.

Por outro lado, Pelè acredita que há precedentes da igualdade humana já nas sociedades pré-modernas ${ }^{7}$. Uma vez que o homem é criado à imagem e semelhança de seu criador e que todos são filhos do mesmo criador, deduz-se que são todos irmãos e, portanto, deverá ter trato mútuo respeitoso, garantidos pela ordem jurídica dos direitos humanos. A superioridade do homem, em relação às outras criaturas, está no caráter da singularidade proveniente da justificação divina e sua hereditariedade originária. Portanto, a dignidade do homem fundamenta-se nas habilidades de poder manifestar sua essência divina.

Segundo Pelè (2004), o conceito moderno da dignidade humana resgata essa ideia de forma secularizada, não decorrente da filiação divina, mas da imanência da própria natureza humana, dada pela sua liberdade e pela autonomia, distanciando-se dessa forma do reino animal ${ }^{8}$. Portanto, para o autor, apesar de sua diferença originária, as duas concepçôes da dignidade humana produzem a mesma consequência: dar um valor absoluto aos seres humanos. No entanto, Pelè (2006) afirma que nas duas dimensóes da dignidade humana há uma tensão inerente à autonomia do indivíduo moderno que pode ser tensionada por uma definição estrita e moral da natureza humana.

5 El concepto de dignidad era asi un concepto religioso y las razones de su aparición deben buscarse en el antropocentrismo fomentado en gran parte por la religión judeo-cristiana. (PELÈ, 2004, p. 2)

6 A esta reformulación parcial del concepto se ha añadido una más profunda: el hombre es un fin en sí mismo y debe ser tratado como tal y no meramente como un medio. Esta nueva formulación de la dignidad se plasmará en el ámbito jurídico con la aparición de los derechos humanos. Desde ahora, la dignidad humana no sólo tiene un alcance vertical (la superioridad de los seres humanos sobre los animales) sino también un alcance horizontal (la igualdad de los seres humanos entre ellos sea cual sea el rango que cada uno pueda desempeñar en la sociedad). (idem, p 10)

7 Si el concepto de dignidad nace en la época pre-moderna, su alcance ha sido desarrollado en la época moderna. De la igualdad de los miembros del género humano se deduce la necesidad de un trato mutuo respetuoso; trato garantizado en particular por las herramientas juridicas que son los derechos humanos. El concepto moderno de dignidad humana es asi deudor del concepto pre-moderno en la medida que recupera esos rasgos humanos pero los interpreta de forma secularizada: el individuo es valioso en si y no por su parentesco divino. Introduce además una novedad: la igual dignidad pretende generar una igualdad jurídica y política de los individuos a pesar de sus posiciones sociales y desigualdades naturales. (Idem)

8 Como podemos ver, esos tipos de fundamentación vincula la dignidad humana con una presumida excelencia natural del ser humano. El valor del ser humano deriva de sus capacidades aunque éstas se manifiestan de distintas formas en cada individuo e incluso, no se manifiestan en ciertos individuos. (PELÈ, 2004, p. 9) 
Al mismo tiempo, existe una tensión entre ambas dimensiones ya que la autonomía inherente que se otorga al individuo moderno puede chocar con una definición estricta y moral de la naturaleza humana. Como señala Taylor existiria hoy un consenso moral, (religioso y laico) que reconoce "algún fundamento en la naturaleza humana o en la situación humana que hace de los seres humanos objetos dignos de respeto" pero no se aceptaría ninguna definición estricta y particular de esta naturaleza humana. (PELÈ, 2006, p. 7)

Por sua vez, Habermas (2010) defende a linha de pensamento que a dignidade da pessoa humana já estaria desde os primórdios numa conexão.

Em oposiçáo à tese de que o conceito de direitos humanos teria recebido retrospectivamente uma carga moral a partir do conceito de dignidade humana, eu gostaria de sustentar a tese de que existiu desde o começo uma conexão conceitual íntima entre ambos os conceitos, ainda que de início apenas implícita. Os direitos humanos sempre foram o produto da resistência ao despotismo, opressão e degradaçâo. (HABERMAS, 2010, p. 4)

Neste sentido o autor defende a ideia que a dignidade humana não é uma sucessão classificatória, um vazio racional, e sim uma fonte moral da qual todos os direitos fundamentais derivam.

Diferentemente de Habermas, Pelè (2004) na sua análise afirma que o indivíduo moderno carrega um "vazio", pelo fato do conceito moderno da dignidade igualar a todos os seres humanos, sem considerar sua filiação, sua origem, posição política e social, rompendo com os fundamentos pré-modernos de dignidade. $\mathrm{Na}$ visão do autor, esse "vazio" da dignidade humana na modernidade, de um lado, estaria vinculado à ausência de fundamentação emocional ${ }^{10}$ e por outro lado, da dificuldade da apreensão do conceito ${ }^{11}$. Portanto, esse "vazio" é decorrente de sua fundamentação filosófica abstrata, de uma perspectiva meramente humanista do homem, onde a sua dignidade deriva de sua razáo e de sua autonomia e o valor do indivíduo encontra-se apenas em seus traços humanos, independentemente da sua condição social, origem e filiação.

9 Spaemann añade más adelante un punto relevante en cuanto la definición moderna de la dignidad: “(...) el ateismo despoja a la idea de dignidad humana de fundamentación (...). No es una casualidad que tanto Nietzsche como Marx hayan caracterizado la dignidad sólo como algo que debe ser construido y no como algo que debe ser respetado". (SPAEMANN, Apud, PELË, 2004, p 10)

10 Cuando nos referimos a un cierto vacio de la dignidad humana, queremos subrayar lo siguiente: mientras que en su forma anterior, el valor del individuo se sostenia en sentimientos que le permitian sentir su identidad, en la modernidad, la dignidad humana parece carecer de fundamento emocional. (PELÈ, 2004, p 10)

11 Por otra parte, el "vacio" relativo al concepto de dignidad humano podría referirse no sólo a la forma cómo uno siente su dignidad sino también en la dificultad de aprehensión del concepto. Dicha dificultad podría derivar del desarraigo de sus elementos constitutivos (razón, autonomía, sociabilidad, sensibilidad, etc.) de cualquier trasfondo religioso.(ibid) 
Por outro lado, Pelè (2004) acredita que não podemos cair no ceticismo sobre o conceito da dignidade humana, uma vez que o problema moderno se apresenta na sua fundamentação abstrata ${ }^{12}$ da dignidade humana. Para o autor a fundamentação da dignidade humana deveria originar-se a partir da problemática em torno do conceito entre o ser e o dever ser.

Segundo o autor, essa problemática já teria aparecido no artigo de Bobbio "Igualdade e dignidade dos homens", quando considerava a igualdade e a liberdade naturais do homem não como um direito, mas como um dever. Decorrente da expressão "nascido com a capacidade de discernir sobre o que se deve fazer e o que não se deve fazer". Posteriormente a mesma ideia teria aparecido em Spaemann quando a expressa através da frase "que a dignidade do homem é inviolável". Segundo o autor neste conceito aparece claramente um dualismo entre o ser e o dever ser.

Robert Spaemann abundó también en un mismo sentido cuando apuntó que este concepto "(..) no indica de modo inmediato un derecho humano especifico, sino que contiene la fundamentación de lo que puede ser considerado como derecho humano en general. Lo que con él se nombre es algo más originario que lo que se expresa por medio del termino derecho humano. $Y$, a la vez, no tiene la misma operatividad que aquel. La frase la dignidad del hombre es inviolable aclara esto de modo inmediato. ¿Quiere ésto decir que la dignidad del hombre no puede o no debe ser violada? El doble sentido de la formulación es un indicio de que el concepto de dignidad humana está asentado en un ámbito precedido por el dualismo del ser y el deber ser". (SPAEMANN, apud, PELÈ, 2004, 12)

\section{A Dignidade Humana Subjacente no Imperativo Categórico Kantiano}

Para Stumpf (2010) a formulação do imperativo categórico de Kant não deve ser entendida como se os dois princípios de universidade e dignidade fossem simplesmente complementares entre si ou fosse apenas o conteúdo da formalidade universal do princípio kantiana.

O constitutivo da dignidade está no fato de que um ser racional não obedece à outra lei senão àquela que ele mesmo simultaneamente se dá. O postulado transcendental da autonomia e a incondicionalidade da

12 Los fundamentos modernos de la dignidad pretenden justificar la dignidad humana únicamente en los rasgos humanos con el fin de justificar la idea de igual dignidad. Igual dignidad que es el fundamento del Estado de Derecho que considera a los individuos como ciudadanos con iguales derechos y deberes. Sin embargo, dichas fundamentaciones tienen poca relevancia práctica: en efecto, por un lado, dan por sentado y obvio que por su excelente naturaleza, el ser humano tiene un valor absoluto y es merecedor de derechos; por otra parte, dicha obviedad choca con las numerosas situaciones actuales y pasadas donde individuos han visto degradado y vulnerado su dignidad. (PELÈ, 2004, p. 11) 
razão, como pressuposto do reconhecimento da universalidade do princípio da dignidade humana, são condição de possibilidade dos direitos fundamentais.

Em Kant, encontramos a base teórica do imperativo categórico não apenas na perspectiva da universalização de princípios, como também correspondendo especificamente ao princípio da dignidade da pessoa humana na sua formulação de que o agir deve sempre ser tal que permita reconhecer o ser humano em si próprio (no sujeito agente) e em todas as pessoas (relação intersubjetiva e social) também como finalidade da ação, e jamais apenas como meio. (STUMPF, 2010, p. 24)

Para o autor, a razão prática em Kant determina a vontade e o agir moral, na interatividade da comunidade de sujeitos éticos encontra seu espaço de atualização e efetividade.

É nessa relação dialética de sujeitos conscientes do valor moral de suas atitudes (pressuposto kantiano do imperativo moral), que a experiência moral se sobrepóe à razão instrumental e tecnicista da modernidade, sem, contudo, pretender postular o princípio da dignidade e liberdade humana como valores absolutos. (IDEM, p. 26)

Igualmente, Pelè (2004) a partir da concepção kantiana sobre a dignidade humana, crê que o fundamento da dignidade humana na modernidade, deve conceber as dimensóes do ser e do dever ser e que essa dualidade inerente ao conceito deve ser analisada numa perspectiva dinâmica, que leve em conta, tanto os elementos constitutivos da dignidade humana e suas manifestaçóes, como um ideal de presente absoluto na natureza e na existência do ser humano ${ }^{13}$ não aceitando nenhuma condicionalidade sobre a dignidade humana.

Segundo o autor, a partir dessa perspectiva o conceito de dignidade humana ganha uma dimensão ontológica, um significado sagrado. Essa concepção impactaria no comportamento intersubjetivo ${ }^{14}$, afetando a existência exterior no mundo físico e na existência interior na pessoa humana.

Cuando hablamos de dignidad humana, nos referimos efectivamente a la "dignidad de la persona", es decir al individuo autónomo y titular de derechos.

13 El concepto moderno de dignidad humana no niega la existencia de desigualdades entre los individuos. Lo que si niega es que esas desigualdades naturales y sociales sean la justificación de un tratamiento desigual por parte de las instituciones o un trato degradante entre los individuos. Con otras palabras, cada uno merece un respeto debido por el mero hecho de ser humano. Tal afirmación recuerda la base de la definición moderna de la dignidad que aparece en Kant: "la humanidad misma es dignidad: porque el hombre no puede ser utilizado únicamente como medio por ningún hombre (ni por otros, ni siquiera por si mismo), sino siempre a la vez como fin, y en esto consiste precisamente su dignidad (la personalidad) en virtud de la cual se eleva sobre todas las cosas (...)"(PELÉ, 2004, p. 11)

14 los individuos deberian tratarse con respeto es decir, siguiendo las palabras de Karl Larenz, reconociendo “(..) la indemnidad de la persona del otro en todo lo que concierne a su existencia exterior en el mundo visible (vida, integridad fisica, salubridad) y en su existencia como persona (libertad, prestigio personal)". (Idem.) 
Esta dimensión contempla estrechamente el concepto de "igual dignidad", que reconoce una igualdad absoluta entre los individuos. Esta igual dignidad probibe en primer lugar, conductas discriminatorias basadas en razones culturales y naturales por ejemplo; es el reducto y el valor último que define por igual a todos los seres humanos, "exigible en sus condiciones reales de existencia"'I5. En segundo lugar, requiere una actitud moral de respeto entre las personas. El fundamento de la "dignidad de la persona" está tradicionalmente vinculado con la pertenencia de todas esas personas a la misma familia humana. (PELÈ, 2006, p. 6-7)

Segundo o autor, historicamente de fato a dignidade humana emerge com mais força diante da vulnerabilidade e do sofrimento. Porém, a ideia da dignidade não deve se fundamentar sobre essa natureza precária do homem, mas de entender como e quando o discurso da dignidade nos campos filosóficos e legais surge. É precisamente quando um indivíduo, um grupo ou até mesmo a espécie humana está em uma situação de vulnerabilidade que o argumento de "dignidade" aparece para resolver esta situação ${ }^{16}$, mas essa não deveria ser o seu fundamento, muito menos os determinismos sociais ou religiosos.

Por otra parte, el concepto moderno de dignidad humana no puede fundamentarse en el único desarraigo del individuo de los anteriores determinismos tanto sociales como religiosos: ello fomentaría ciertamente la libertad del ser humano pero no lo ayudaría a encontrar un sentido a su identidad. (PELÈ, 2004, p. 13)

\section{Dignidade Humana como Fonte Moral dos Direitos Humanos}

Habermas (2010) por sua vez acredita que ao longo da história há um vínculo estreito entre os conceitos de dignidade humana e direitos humanos, que fundamentam a construção realista pela via democrática. Perlatto (2013) defende a mesma linga de raciocínio quando afirma que a dignidade humana na modernidade se tornaria a fonte moral dos direitos humanos individuais construídos pela via da democracia cosmopolita.

Daí, sua perspectiva normativa se fundar na possibilidade da construção de uma agenda democrática cosmopolita que assuma estes dois conceitos como ancoragem e que seja capaz de construir instituiçóes, reunindo Estados e cidadãos do mundo, capazes de defendê-los e ampliá-los. Da mesma forma que a junção desses conceitos teria tido um "papel catalisador” para impulsionar, no curso da história, diversas transformaçóes

15 DÍAZ E., Un itinerario intelectual. De filosofía jurídica y política, Biblioteca Nueva, Madrid, 2003, p. 10.

16 La vulnerabilidad humana debe tenerse en cuenta a la hora de identificar los rasgos de la naturaleza pero no puede constituir el fundamento de la dignidad. (PELÈ, 2004, p. 13) 
democráticas, elas permaneceriam como as vigas de suporte de um projeto no qual, a partir da "força civilizadora do direito estabelecido democraticamente” (p.45), seria possível assegurar a construção de uma ordem democrática para a sociedade mundial contemporânea. (PERLATTO, 2013, p. 47)

Reconhecemos que a história do homem confunde-se com a luta para a preservação da dignidade humana e dos direitos humanos que foram, a partir de sua concretude histórica, dando contornos emancipatórios, principalmente contra as violações dos direitos sociais, políticos, civis, culturais, econômicos, ambientais construindo novos parâmetros de equidade social.

Para Dornelles (2007) a evolução dos direitos humanos se dá no processo de privação e conscientização:

Cada geração de direitos humanos nasceu e se desenvolveu representando momentos históricos onde os indivíduos, os oprimidos, os explorados, os injustiçados, os expropriados levantaram a bandeira da libertação e da emancipação humana, conquistando durante espaços democráticos e liberdades possíveis no contexto histórico vivido. (DORNELLES, 2007, p. 67)

Nesta mesma perspectiva, Cittadino (2000) corrobora com a construção cidadã do Estado Democrático de Direito, quando afirma:

é possível lutar pela conformaçáo de uma identidade política comum, desde que possamos adotar uma compreensão procedimental da Constituição e não torná-la como uma "ordem concreta de valores". Neste sentido, é preciso que sejamos capazes de perceber, por um lado, que fomos capazes de reconstruir o Estado de Direito, e por outro lado, que a Constituição, neste processo, representa um consenso procedimental em torno de princípios jurídicos universais cuja implementação e inscrição em nossa história política depende dos processos de formação da opinião e da vontade nos quais a soberania popular assume forma política. (CITTADINO, 2000, p. 231)

A história do homem confunde-se com a luta para a preservação dos direitos humanos que foram a partir de sua concretude histórica dando contornos emancipatórios, principalmente contra as violaçóes dos direitos sociais, políticos, civis, culturais, econômicos, ambientais construindo novos parâmetros de equidade social.

Para Dallari (2012) o estado democrático é um ideal possível de ser atingido, desde que seus valores e sua organização sejam concebidos adequadamente. Na visão do autor o pressuposto fundamental do estado democrático possível seria um Estado dotado de uma organização flexível, que assegure a permanente supremacia da vontade popular, e busque a preservação da liberdade e a preservação da igualdade. 
Para Boff (2003)

a centralidade da nova concepção reside em dar-se conta da complexidade da realidade. Junto ao sabido está sempre o não sabido; o contrário e antagônico não são negadores do real, mas manifestaçôes de sua pluridimensionalidade; caos e ordem se pertencem mutuamente. (BOFF, 2013, p. 31)

Para Boff (2003), ao lado do espírito e da matéria entra em consideração especialmente a vida com sua lógica não-linear, com sua complexidade, organicidade e auto-regulação. Conta mais a perspectiva sintético-holística que a analítica, o ser humano não é apenas espectador passivo do espetáculo do mundo, mas ator ativo, sendo sempre incluído na ciência e na pesquisa, por mais objetivas que pretendam ser.

Segundo Boff (2003), neste momento, a história da humanidade passa por uma crise radical. Em termos abstratos percebe-se a crise do paradigma moderno, mas que na concretude histórica manifesta-se como a crise do sonho, da utopia que deu sentido ao mundo nos últimos séculos.

O projeto da modernidade assentado no antropocentrismo, na racionalidade instrumental do domínio da natureza a qualquer custo, a busca de um crescimento econômico ilimitado, a vontade de poder como dominação sobre os outros, sobre povos e sobre a própria natureza chegam ao esgotamento humano e ambiental.

Para Boff (2003) os cientistas já apontam há muito tempo que para evitar uma crise irreversível a solução do equilíbrio não é científico e tecnológico, e sim, político e social. O equilíbrio sustentável é incompatível com uma economia mundial baseada na busca ilimitada do lucro por empresas econômicas competindo globalmente.

O paradigma desta sociedade se expressou em dois sistemas sociais antagônicos: o capitalismo e o socialismo. O primeiro privatizou os bens e socializou os sonhos e o segundo socializou os bens e privatizou os sonhos.

Os dois sistemas tendo o paradigma de poder como dominação do mundo e dos povos levaram a três desvios que marcam profundamente nossa cultura hoje mundializada, o reducionismo na concepção do ser humano, o recalque do feminino e o desrespeito à alteridade e à natureza.

O ser humano mais e mais se descobre como parte da natureza e membro da comunidade de vida. Sua relação não pode ser de dominação, mas de convivência numa nova aliança de respeito e de diálogo. O ser humano precisa de natureza para seu sustento e ao mesmo tempo a natureza, marcada pela cultura, precisa do ser humano para ser preservada e para poder manter ou recuperar seu equilíbrio. Portanto, para Boff (2003) todos os seres da natureza são sujeitos de direito, são portadores de informação e de subjetividade. 
Kant, ao defender a legitimação da liberdade e da igualdade da dignidade humana na forma de princípio moral, possibilita uma consideração de temas tradicionalmente relegados como sendo metafísicos e por isso, tidos sem valor científico. Stumpf (2010) defende que a dignidade humana não pode ser refém do cientificismo abstrato, uma vez que a consciência humana tem na sua essência o fator moral com fundamento seu agir humano. Mesmo com todo o desenvolvimento científico em tordo da evolução humana através da neurociência, do estudo do cérebro humano, na dissecação dos neurônios, essas ciências empíricas jamais conhecerão a consciência humana, a sua dignidade humana. "Aliás, sua existência humana é tão certa como a afirmação ou a negação de sua existência. E aí, situa-se o fator moral, pois, se pela consciência o ser humano sabe e sabe que sabe, o conhecimento moral é o núcleo dessa consciência” (STUMPF, 2010, p. 38).

\section{Conclusões}

No decorrer da nossa analise sobre os desafios da fundamentação da dignidade humana, vimos que para Habermas (2010) “o conceito filosófico de dignidade humana, que surgiu na Antiguidade e adquiriu sua formulação atual em Kant”, originou-se devido as enormes atrocidades cometidas em nome dos direitos humanos, durante a Segunda Guerra Mundial, e que a partir de lá tem recebido destaque especial nas constituiçóes nacionais e nos textos do direito internacional.

Segundo Pelè, historicamente houve várias tentativas de uma aproximação conceitual contemporânea sobre a dignidade humana, essa, no entanto, não aceita uma explicação racional para o fundamento da dignidade humana, devida a sua complexidade subjetiva e mutável, o que ocasionado um "vazio" conceitual. Diante deste embate teórico, Pelè procura descrever as várias fases do conceito de dignidade humana passando pela era prémoderna onde o homem é concebido como a imagem de seu criador até a era moderna onde o conceito da dignidade humana deriva de sua natureza humana, dissociado de qualquer origem divina, mantida a sua singularidade da espécie humana em relação aos outros animais.

Diferentemente de Habermas, Pelè na sua análise afirma que o indivíduo moderno carrega um "vazio", pelo fato do conceito moderno da dignidade igualar a todos os seres humanos, sem considerar sua filiação, sua origem, posição política e social, rompendo com os fundamentos pré-modernos de dignidade. Na visão do autor, esse "vazio" da dignidade humana na modernidade, de um lado, estaria vinculado à ausência de fundamentação emocional e por outro lado, da dificuldade da apreensão do conceito.

Sobre a visão a concepção moderna da dignidade humana, Stumpf (2010) argumente que a formulação do imperativo categórico de Kant não deve ser entendida como se os dois princípios de universidade e dignidade fossem simplesmente complementares 
entre si ou fosse apenas o conteúdo da formalidade universal do princípio kantiana. Para o autor a razão prática em Kant determina a vontade e o agir moral, na interatividade da comunidade de sujeitos éticos encontra seu espaço de atualização e efetividade.

Finalmente vimos que Habermas acredita que ao longo da história há um vínculo estreito entre os conceitos de dignidade humana e direitos humanos, que fundamentam a construçáo realista pela via democrática e que Perlatto defende a mesma linga de raciocínio quando afirma que a dignidade humana na modernidade se tornaria a fonte moral dos direitos humanos individuais construídos pela via da democracia cosmopolita.

Concluímos que na sociedade contemporânea os direitos do ser humano e da sociedade chegam à convicção ética de que a pessoa humana é sempre um fim e jamais um meio e de que todo o poder somente se legitima à medida que se faz mediaçáo da justiça e do bem comum dos cidadãos e da natureza. Que todo desenvolvimento técnico deve ser orientado para a promoção integral da pessoa humana e dos povos.

\section{Referências}

BOBBIO, Norberto. A era dos direitos, trad. de Carlos Nelson Coutinho, São Paulo: Ed. Elsevier, 2004.

Direito e Estado no Pensamento de Emanuel Kant. 2o ed., Tradução de Alfredo Fait. São Paulo: Mandarim, 2000.

BOFF, Leonardo. Civilizaçâo planetário: desafios à sociedade e ao cristianismo. Rio de Janeiro: Sextante, 2003.

CITTADINO, Gisele. Pluralismo, direito e justiça distributiva. Rio de Janeiro: Lúmen Júris, 2000.

DALLARI, Dalmo de Abreu. Elementos de teoria geral do Estado. São Paulo: Saraiva, 2012.

DORNELLES, João R. W. O que são Direitos Humanos. São Paulo: brasiliense, 2007.

HABERMAS, Jürgen, O Conceito de Dignidade Humana e a Utopia Realista dos Direitos Humanos. Trad. de Eduardo Mendonça e Letícia de Campos Velho Martel, do original, "The Concept of Human Dignity and the Realistic Utopia of Human Rights", Metaphilosophy, Vol. 41, Núm. 4, 2010, pp. 464-480.

HALL, Stuart, A identidade cultural na pós-modernidade, trad. de Tomaz Tadeu da Silva \& Guacira Lopes Louro, Rio de Janeiro: Ed. Lamparina, 2014.

LIOGIER, Raphaël, "Laïcité on the edge in France: Between the theory of Church-State Separation and the Praxis of State-Church Confusion", Macquarie Law Journal, Vol. 9, 2009, pp. 25-45. 
PELÈ, Antonio. Filosofia e Historia En El Fundamento De La Dignidad Humana. Tesis Doctoral. Universidad Carlos III de Madrid. Instituto De Derechos Humanos "Bartolomé De Las Casas". Getafe, julio de 2006.

. Una aproximación al concepto de dignidad humana. Universitas: Revista de Filosofía, Derecho y Política, n. 1, diciembre-enero 2004, p. 9-13 - ISSN: 1698-7950.

PEREZ, González Jesús La dignidad de la persona. Madrid: Civita, 2011.

PERLATTO, Fernando. A utopia realista de Habermas: Cosmopolitismo, dignidade humana e direitos humanos. BOLETIM CEDES - ABR/JUN 2013 - ISSN 19821522

SANTOS, Boaventura de Sousa. Se Deus fosse um ativista dos direitos humanos. São Paulo: Ed. Cortez, 2013.

STUMPF, Paulo Umberto. O princípio Constitucional da Dignidade Humana. Fundamentos Éticos e Morais. Belo Horizonte: Editora o Lutador, 2010. 